\title{
Eja: percepção de autonomia dos alunos nas aulas de educação física
}

\author{
Ana Luiza Barbosa Anversa ${ }^{1}$ \\ Yedda Maria da Silva Caraçato de Sousa ${ }^{2}$ \\ Bruna Solera ${ }^{3}$ \\ Luciane Arantes da Costa ${ }^{4}$ \\ Patric Paludett Flores ${ }^{5}$ \\ Amauri Aparecido Bássoli de Oliveira ${ }^{6}$ \\ Vânia de Fátima Matias de Souza ${ }^{7}$
}

\begin{abstract}
Resumo: Os documentos educacionais indicam a busca por uma educação que vise a formação em prol da autonomia do sujeito. Nessa premissa, a presente pesquisa, do tipo qualiquantitativa, teve como objetivo analisar de que maneira o desenvolvimento do trabalho pedagógico realizado no campo da educação física é percebido pelos alunos da EJA como uma ação que apoia o desenvolvimento de sua autonomia, em relação às situações de aprendizagem vivenciadas. Para isso, foi aplicado o "Questionário de Clima de Aprendizagem" em 150 alunos regularmente matriculados. Foi identificado alto índice de percepção de autonomia nas situações de aprendizagem, demonstrando haver uma incorporação e/ou consolidação das representações e percepções dos alunos acerca do sentido autônomo para o aprender, valorizando a relevância da ação pedagógica vinculada entre os conteúdos de ensino e as questões sociais.
\end{abstract}

Palavras-chave: Educação Básica. Educação Física. Educação de Jovens e Adultos. Autonomia.

\section{YAEP: Perception of autonomy students of physical education classes}

\footnotetext{
${ }^{1}$ Doutora em Educação Física pelo Programa de Pós Graduação Associado em Educação Física UEM/UEL. Professora do Departamento de Educação Física do Centro Universitário Metropolitano de Maringá e Universidade Estadual de Maringá. ana.beah@gmail.com.

${ }^{2}$ Licenciada em Educação Física pela Universidade Estadual de Maringá. Bacharel em Educação Física pelo Centro Universitário Inta. Mestranda em Educação Física pelo Programa de Pós Graduação Associado em Educação Física UEM/UEL. yeddacaracato@hotmail.com.

${ }^{3}$ Mestre em Educação Física pela Universidade Estadual de Maringá. Doutoranda em Educação Física pelo Programa de Pós Graduação Associado em Educação Física UEM/UEL. brunasoleraef@ gmail.com.

${ }^{4}$ Doutora em Educação Física pelo Programa de Pós Graduação Associado em Educação Física UEM/UEL. Professora do programa de Pós Graduação Associado em Educação Física UEM/UEL, do programa do mestrado profissional em Educação Física em rede (PROEF) e do Departamento de Educação Física da Universidade Estadual de Maringá. luarantes100@gmail.com.

${ }^{5}$ Doutor em Educação Física pelo Programa de Pós Graduação Associado em Educação Física UEM/UEL. Professor do Departamento de Educação Física da Universidade Estadual do Paraná. patricpflores@ gmail.com.

${ }^{6}$ Doutor em Educação Física pelo Universidade Estadual de Campinas, Professor do programa de Pós Graduação Associado em Educação Física UEM/UEL e da Universidad Católica del Maule. amauribassoli@gmail.com.

${ }^{7}$ Doutora em Educação. Professora do programa de Pós Graduação em Educação da Universidade Estadual de Maringá, do programa do mestrado profissional em Educação Física em rede (PROEF) e do Departamento de Educação Física da Universidade Estadual de Maringá. vfmatias@ gmail.com.
} 


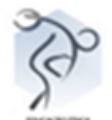

Abstract. The educational documents advocate the search for an education with a view to training for the autonomy of the subject. Therefore, the present research, of the qualitauantitative type, aimed to analyze how the development of pedagogical work carried out in the field of physical education is perceived by the students of the EJA as an action that supports the development of their autonomy in relation to learning situations. For this, the "Learning Climate Questionnaire" was applied to 150 regularly enrolled students. A high level of perception of autonomy in learning situations was identified, demonstrating that there is an incorporation and / or consolidation of the students' representations and perceptions about the autonomous sense to learn, valuing the relevance of the pedagogical action linked between the teaching contents and the questions social policies.

Palavras-chave: Basic Education. Physical Education. Youth and Adult Education. Learning climate.

\section{INTRODUÇÃO}

Discutir as relações entre os saberes científicos e suas influências na construção da autonomia do sujeito para "o aprender", tem se tornado uma constante reflexão pedagógica no contexto das discussões no campo da formação do sujeito e da prática docente. Para compreendermos a referência dada ao conceito de autonomia no contexto educacional, apoiamo-nos nas descrições de Castoriadis (1991), cuja visão denota a compreensão de que a autonomia nada mais é que um empreendimento da humanidade e um programa de reflexão filosófica sobre o indivíduo; destacando o fato de que a autonomia, se trata da "minha lei, oposta à regulação pelo inconsciente que é uma outra lei, a lei de outro que não eu". (CASTORIADIS, 1991, p. 123).

A autonomia está agregada a um conjunto de valores e normas sociais e culturais, cuja delimitação e aquisição só se dão a partir das possibilidades e limites para o seu exercício. A autonomia do sujeito está atrelada a sua relação social, logo "não podemos desejar a autonomia sem desejá-la para todos e sua realização só pode conceber-se como empreitada coletiva" (CASTORIADIS, 1991, p. 130).

$\mathrm{Na}$ ação cotidiana do campo escolar essa autonomia acaba se constituindo em um movimento espiralado, cuja práxis do seu exercício se dá pela construção coletiva, por meio de contextos elucidados constantemente, isto porque, a autonomia é uma relação intrínseca entre o que é visado e desejado pelo sujeito e a relação do mesmo com o processo educativo ofertado. Nessa complexidade, a autonomia se constituí a partir dos antagonismos dados nas relações sociais, cujo embate esteja atrelado ao paradigma social do governar-se a si próprio. 
De acordo com Gadotti (1992) no âmbito da educação, o debate moderno em torno do tema está atrelado ao processo dialógico de ensinar, no qual se preconiza a capacidade do educando em buscar resposta às suas próprias perguntas, exercitando, portanto, sua formação autônoma. Nesse contexto, a educação vai gradativamente possibilitando a noção de autonomia dos alunos e da escola, muitas vezes compreendida como autogoverno, autodeterminação, auto formação, autogestão, resultando assim, em uma forte tendência na área.

Como consequência a essa busca por uma educação com a sustentação em uma ação dialógica que coaduna no campo da formação humana em busca da autonomia, do ser que vive no coletivo, os "modos" operante do ensinar e do aprender têm se constituído em um emaranhado constante de transformações, resultando em experimentações didáticopedagógicas ora refletidas em tendências pedagógicas, ora evidenciadas nos processos interventivos escolares. Logo, esse tema por vezes abordado no bojo da produção das teorias que fundamentam as denominadas pedagogias libertárias, pedagogias ativas e as que defendem, de modo geral, a individualização ou personificação do ensino (UNESCO, 1981).

Nesse contexto de formação escolar com vista à formação humana, o ensino em suas modalidades e níveis acabam apresentando peculiaridades distintas, de acordo com cada realidade. Como exemplo, podemos citar a Educação de Jovens e Adultos (EJA), na qual, o ensino é direcionado, aos que não tiveram a oportunidade de completar sua formação básica na idade regular (BRASIL, 1996).

A opção por buscar entender, a formação humana pelo ensino autônomo nesse contexto, se dá pelo fato desta modalidade de ensino ser caracterizada pelos grandes índices de evasão escolar, talvez como reflexo da falta de autonomia dada aos alunos, esse indicativo se evidenciou como uma fonte inquietadora na nossa pesquisa. Vale ressaltar que de acordo com Mello (1993) a evasão escolar é causada tanto por variáveis extraescolares como interescolares, decorrentes de práticas administrativas e docentes, fato este que torna de suma relevância a realização de uma análise constante dos recursos didáticos empregados, das ações mediativas adotadas ao longo do processo e qual a forma de ensinar adotada pelo professor.

Isto porque, segundo Decin e Ryan (2000) é muito importante que os professores busquem no cotidiano das aulas, estabelecer ações que viabilizem o apoio à autonomia, que 


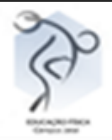

com base na teoria da Autodeterminação são ações inerentes ao aprofundamento do conhecimento por meio da motivação do estudante, sendo que quanto maior o envolvimento nas tarefas, mais motivado intrinsecamente o aluno se apresenta, ou seja, as razões do envolvimento na atividade ocorrem fortemente em função do interesse e satisfação do aluno.

Desta forma o fortalecimento da motivação intrínseca dos alunos se coloca como uma das estratégias para o envolvimento dos mesmos na ação pedagógica. Essa ação pode se dar a partir do conhecimento dos interesses, conhecimentos prévios e expectativas dos mesmos, de modo a incentivá-los a fazer parte da proposta pedagógica apresentada e compartilhar suas expectativas e agruras em relação aos conteúdos propostos (SOUZA, 2012).

A EJA tem como finalidade e objetivo o compromisso com a formação humana, disponibilizando ações que fomentem o acesso à cultura geral, de modo que os educandos venham a participar política e produtivamente das relações sociais, por meio do desenvolvimento da autonomia intelectual e moral (BRASIL, 1996).

Assim, ao fazer uma investigação na literatura da área, nota-se que existem poucos estudos sobre o clima de aprendizagem (RODRIGUES; MOURA, 2016; DA COSTA et al., 2016; MESQUITA et al.,2016) em especial no contexto das aulas de educação física na EJA, componente curricular facultativo que acaba por assumir diferentes representações neste contexto de ensino e, por conseguinte, atingir o trabalho do professor e o envolvimento dos alunos (GOLDSCHMIDT FILHO; CRUZ; BOSSLE, 2016; GÜNTHER, 2016). Isto porque, no contexto educacional, o clima de aprendizagem é um elemento importante para a melhora da motivação, persistência, emoções e comportamento dos alunos ao longo do processo de ensino e de aprendizagem, uma vez que pode favorecer a criação de vínculos afetivos tornando este momento mais prazeroso para o aluno. Gregory (2008) aponta que o clima de aprendizagem pode ser influenciado pela forma de ensinar do professor e pelos atributos físicos da escola, como iluminação, ventilação e recursos materiais.

Direcionando para ação interventiva do professor, nota-se que, para que o processo de ensino e de aprendizagem se configure de forma satisfatória e favorável ao clima de aprendizagem é necessário que os alunos se sintam partícipes das ações propostas, por isso é de suma importância que o professor procure estabelecer relações concretas entre os conteúdos estudados e a realidade apresentada, elevando o interesse e satisfação dos alunos de 


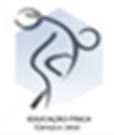

modo a garantir a assimilação e inter-relação na construção da aprendizagem (RODRIGUES; MOURA, 2016).

Ames (1992) e Reeve e Jang (2006) verificaram que ao promover autonomia e ouvir os alunos, o professor acaba por influenciar o aluno a estabelecer metas e, com isso, favorece sua motivação intrínseca ${ }^{8}$ tendo, por consequência, o envolvimento nas tarefas propostas e busca colaborativa por soluções.

Diante disso, o presente estudo objetivou analisar de que maneira o desenvolvimento o trabalho pedagógico realizado no campo da educação física escolar é percebido pelos alunos da EJA como uma ação que apoia o desenvolvimento de sua autonomia, em relação as situações de aprendizagem.

\subsection{As nuances históricas da educação de jovens e adultos no Brasil e indicativos do apoio à autonomia nas aulas de Educação Física}

Para entender as relações estabelecidas nos processos de ensino da EJA, há que se compreender inicialmente o fato de que essa é uma modalidade de ensino na educação brasileira se deu segundo Viegas e Moraes (2017), como uma modalidade de ensino advinda de ações governamentais que tinham como meta combater os altos índices de analfabetismo vistos como entrave à economia do país no século XIX. Os primeiros moldes didáticopedagógicos adotados por essa modalidade de ensino não atendiam aos anseios da população que necessitava desta oferta educacional, já que as estratégias não incentivavam a participação e reflexão crítica e seguiam os preceitos da alfabetização de crianças.

De acordo com Paulo Freire essa modalidade de ensino, é um meio de conscientização política e emancipação humana, pois facilita ao aluno desvelar o mundo ao longo do processo de construção do conhecimento, fazendo uma leitura crítica da realidade a partir de saberes necessários que os possibilitem formas competente de intervenção gnosiológica e política (FREIRE, 1991).

\footnotetext{
${ }^{8}$ Com base na Teoria da Autodeterminação (Deci; Ryan, 2000), quando motivado intrinsecamente o individuo apresenta razões internas para o envolvimento na atividade.
} 


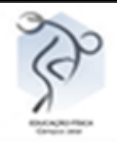

Normatizada pela Lei de Diretrizes e Bases da Educação Nacional (LDBEN) n.9.394 de 1996, a educação de jovens e adultos como modalidade de educação básica, fomentando reflexões, entre os pesquisadores da educação, sobre as necessidades peculiares desta modalidade de ensino que tem como principal público, trabalhadores, aposentados, jovens e adolescentes empregados ou em busca de emprego e pessoas com necessidades educativas especiais (SOUZA, 2012; VIEGAS; MORAES, 2017).

Essas reflexões e discussões resultaram nas Diretrizes Curriculares Nacionais para a Educação de Jovens e Adultos, Parecer CNE/CEB 11/2000 e Resolução CNE/CEB 01/2000, como estratégia de atender as especificidades deste seguimento educacional e melhorar a qualidade do ensino ofertado, demandando dos professores saberes e ações que passassem a valorizar o sujeito com o qual trabalhavam.

Desde modo, passou-se a defender a postura de um professor que fomentasse a postura crítica e participativa do aluno, levando-os a superarem-se constantemente, configurando o ato educativo como um ato de conhecimento que aproximasse os conteúdos científicos das experiências e necessidades dos educandos (SOUZA, 2012).

Com isso, emerge a necessidade de se pensar as estratégias para viabilizar um clima de aprendizagem adequado, de forma a apoiar e promover a autonomia, uma vez que a literatura aponta que a falta de apoio à autonomia está fortemente correlacionada com a desmotivação dos estudantes (MAZYARI et al., 2012; SHEN et al. 2010).

Quando o professor oferece apoio à autonomia, o clima de aprendizagem torna-se adequado, tendo como consequência o aumento da motivação intrínseca dos estudantes. Ao contrário, quando o clima de aprendizagem é inadequado ou controlado, os professores não fornecem respostas significativas para o processo de ensino e aprendizagem (AMES, 1992).

No contexto da Educação Física, na atual configuração da EJA, o processo de ensino e de aprendizagem pauta-se na flexibilidade da organização curricular de modo a adequar os conteúdos programáticos às características biográficas dos educandos. Para isso a ação dos professores, precisa sustentar-se em uma prática pedagógica pautada no diálogo e interação entre o educador e o educando, para que a prática educativa se assume como coletiva e viabilize o apoio à autonomia. 


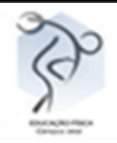

Os alunos da EJA, por suas características etárias e funcionais, possuem ideias constituídas e trazem uma experiência de vida ampliada, por isso torna-se necessário que o professor valorize em suas aulas além dos aspectos cognitivos as questões afetivas, para que o aluno se sinta acolhido e administre sua aprendizagem. Segundo Moura (2016) as aulas nessa modalidade de ensino devem procurar trabalhar com dinâmicas e jogos, que envolvam encantamento e aprendizagem ao mesmo tempo.

Esse cenário é algo próximo da Educação Física, que direciona suas ações interventivas para o movimentar humano. Neste movimentar há a necessidade do sentido individual e coletivo, levando o sujeito a se reconhecer como ator e autor da sua própria história e das relações sociais estabelecidas (MOREIRA; CHAVES; SIMÕES, 2017), ou seja, não se pode trabalhar ao longo das aulas o movimento meramente mecânico e repetitivo, é preciso refletir esse movimento e sua relação com aspectos antropológicos, psicológicos e biológicos.

Morin (2001) destaca que o movimento humano está atrelado às autonomias individuais e a participação em comunidade, o que se reflete na aprendizagem e no ser e estar no mundo. Deste modo, cabe ao professor, nas situações de aprendizagem, estimular a autonomia dos alunos, mesmo com as barreiras enfrentadas pela área na educação básica e em especial na EJA.

Goldschmidt Filho, Cruz e Bossle (2016) apontam que a Educação Física na EJA esbarra em questões legislativas, já que a LDBEN 9.394/96 no inciso $3^{\circ}$ apresenta pontos que tornam a participação nas aulas facultativa, e que comumente se enquadram no perfil dos alunos desta modalidade. Essa facultatividade do componente curricular talvez se dê pela imagem fortemente atrelada ao aspecto biológico que a área ainda carrega o que por vezes dificulta o trabalho do professor e uma postura didática aberta a trocas de experiência.

Deste modo, os professores podem utilizar a condição heterogenia da constituição dos grupos de EJA nas aulas de Educação Física, já que "ao levar em consideração as diferentes biografias dos alunos, as diferentes formas de manifestação da cultura corporal de movimento trazida por eles, estão se abrindo possibilidades para que todos possam aprender" (MOREIRA et al., 2017, p.124), construindo-se o verdadeiro conhecimento que pode levar a humanização. 
A teoria da autodeterminação evidencia que o apoio à autonomia pode contribuir para a melhoria da motivação e percepção de competência dos indivíduos. No ambiente escolar, os professores podem colaborar em uma formação mais adequada se souberem fornecer apoio à autonomia de seus alunos. No âmbito da Educação Física, estudos têm demonstrado que os alunos mais motivados nas aulas participam efetivamente das atividades e acreditam em sua importância (CARREIRO DA COSTA et al., 1997; CERVELLÓ, 1999).

Frente ao exposto, torna-se necessário possibilitar aos professores e alunos como esses percebem as ações educativas com foco no desenvolvimento de sua autonomia no contexto da Educação de Jovens e Adultos, em especial, nas aulas de Educação Física.

\section{METODOLOGIA}

A presente pesquisa se caracterizou como qualiquantitativa do tipo descritiva, que permite identificar as características do objeto de estudo de forma objetiva e completa sem manipulação dos mesmos (THOMAS; NELSON, 2002).

A população investigada foi a de alunos da EJA, vinculados a um Centro Estadual de Educação Básica para Jovens Adultos (CEEBJA) da cidade de Maringá-Paraná, selecionado de modo intencional, uma vez que, neste tipo de seleção o pesquisador pode ter acesso a informações mais qualificadas sobre seu objeto de pesquisa por se tratar de um contexto propício para o desenvolvimento da mesma (MAYAN, 2001).

A amostra foi composta por 150 alunos sendo, 60 do sexo masculino e 90 do sexo feminino. O convite para participar da pesquisa se deu mediante a autorização da pedagoga responsável e foi feito a todos os alunos regulamente matriculados no período vespertino, em horário de aula e em dia previamente agendado junto à direção. Para compor a amostra se fez necessário ter mais de 18 anos, já ter cursado o módulo correspondente à educação física e assinar o Termo de Consentimento Livre Esclarecido (TCLE).

Como instrumento de coleta de dados foi utilizado o Learning Climate Questionnaire (LCQ) construído por Deci e Ryan (2011), e validado para a língua portuguesa pôr da Costa et al. (2016). O questionário tem como objetivo verificar a percepção dos alunos em relação ao apoio à autonomia nas situações de aprendizagem durante suas aulas, 


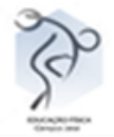

compreendendo 15 itens relacionados a situações específicas de aprendizagem e levando em consideração o clima de aprendizagem e a forma de ensinar do professor.

Os resultados decorrentes da análise estatística descritiva (frequência e percentual) e da análise inferencial para a comparação da percepção de apoio à autonomia em relação ao sexo (teste U de Mann-Whitney) subsidiaram uma análise qualitativa sobre os possíveis reflexos da ação docente na percepção da autonomia dos alunos.

Por fim, destaca-se que todos os participantes foram informados sobre a divulgação e publicação das informações coletadas na pesquisa, sendo obtido o consentimento dos sujeitos. E que a pesquisa se vinculou ao projeto Educação Física Escolar: perspectivas e ações pedagógicas na atualidade do grupo de estudos e pesquisa em educação física escolar (GEEFE- CNPq), sendo aprovada pelo Comitê Permanente de Ética em pesquisa COPEP por meio do parecer $n^{\circ} 1.715 .040$.

\section{RESULTADOS E DISCUSSÕES}

Ao ler o Projeto Político Pedagógico da instituição, buscou-se o perfil sócio demográfico dos alunos da instituição de ensino. O documento destaca que dentre os alunos regulamente matriculados $51 \%$ são do sexo feminino e $47 \%$ do sexo masculino, $29 \%$ encontram-se na faixa etária de 31 a 50 anos, $28 \%$ de 18 a 21 anos, 27\% de 22 a 30 anos, 8\% de 15 a 17 anos e $8 \%$ possuem mais de 50 anos. O maior índice de alunos do sexo feminino se refletiu no perfil da amostra da pesquisa. O Projeto Pedagógico destaca ainda que a taxa de abandono do processo de ensino aprendizagem é de 10,81\%.

Sobre o perfil socioeconômico dos alunos, a maioria é de trabalhadores, de classe média baixa e ganham até um salário mínimo por mês. Alguns também são integrantes do programa bolsa família e veem na EJA a possibilidade de conseguirem um melhor emprego e remuneração, alguns também sonham em ingressar em um curso superior.

No que se refere à percepção dos alunos em relação ao incentivo à autonomia durante as aulas, a Tabela 01 apresenta as frequências $(f)$ e percentuais (\%) de cada item do questionário em suas categorias: realmente discordo (RD), discordo (D), não concordo nem discordo (NC/ND), concordo (C) e realmente concordo (RC). 


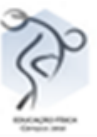

Tabela 01: Percepção dos alunos da EJA em relação ao apoio à autonomia dos professores nas aulas de

Educação Física

1- Eu sinto que meu professor me oferece escolhas e opções

\begin{tabular}{cccccccccr}
\multicolumn{2}{c}{ RD } & \multicolumn{2}{c}{$\mathbf{D}$} & \multicolumn{2}{c}{ N/C N/D } & \multicolumn{3}{c}{$\mathbf{C}$} & \multicolumn{2}{c}{ RC } \\
$(f)$ & $(\%)$ & $(f)$ & $(\%)$ & $(f)$ & $(\%)$ & $(f)$ & $(\%)$ & $(f)$ & $(\%)$ \\
8 & 5,3 & 3 & 2 & 40 & 26,7 & 17 & 11,3 & 82 & 54,7
\end{tabular}

2- Eu sinto que meu professor me compreende

RD

$(f)$

5

D

N/C N/D

C

RC

$(f) \quad(\%) \quad(f)$

$(f)$

32,7

20

$(\%)$

$(f)$

$(\%)$

0,7

49

13,3

50

3- Eu sou capaz de me expressar com meu professor durante as aulas

RD

$(f)$

14
D

N/C N/D
C
RC
$\quad(\%)$
$(f)$
$(\%)$
(f) $\quad(\%)$
$(f)$
$(\%)$
$(f)$
$(\%)$
4
9,3
$2 \quad 1,3$
32
$21,3 \quad 14$
$9,3 \quad 88$
58,7

4- Meu professor mostrou confiança na minha capacidade de ter bom desempenho nas aulas

\begin{tabular}{cccccccccr}
\multicolumn{2}{r}{ RD } & \multicolumn{2}{c}{ D } & \multicolumn{2}{c}{ N/C N/D } & \multicolumn{2}{c}{ C } & \multicolumn{2}{c}{ RC } \\
$(f)$ & $(\%)$ & $(f)$ & $(\%)$ & $(f)$ & $(\%)$ & $(f)$ & $(\%)$ & $(f)$ & $(\%)$ \\
5 & 3,3 & 1 & 0,7 & 36 & 24 & 26 & 17,3 & 82 & 54,7
\end{tabular}

5- Eu sinto que meu professor me aceita

RD

D

N/C N/D

C

RC

(f)

$(\%) \quad(f)$

(\%)

(f)

(\%)

(f)

(\%)

(f)

(\%)

1

0,7

2

$14 \quad 9,4$

19

12,7

113

75,3

6- Meu professor se certifica se entendi os objetivos da aula e o que eu tenho que fazer

RD

D

N/C N/D

C

RC

$(f)$

$(\%)$

(f)

$(\%)$

(f) $\quad(\%)$

(f)

$(\%)$

(f)

$(\%)$

1

0,7

0,7

27

18

23

15,3

98

65,3

7- Meu professor me encorajou a fazer perguntas

RD

D

N/C N/D

C

RC

(f)

$(\%)$

(f)

$(\%)$

(f)

(\%)

(f)

(\%)

(f)

23,3

30

20

74

(\%)

49,3

8- Eu sinto muita confiança no meu professor

RD

D

N/C N/D

C

RC

(f)

(\%)

$(f)$

$(\%)$

$(f)$

$(\%)$

$(f)$

$(\%)$

$(f)$

$(\%)$

3

2

0,7

17,3

26

$17,3 \quad 94$

62,7

9- Meu professor responde minhas perguntas de forma completa e cuidadosa

RD

D

N/C N/D

C

RC 


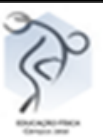

(f)

$(\%) \quad(f)$

(\%)

(f)

$(\%)$

(f)

(\%)

(f)

(\%)

2

1,3

1,3

$20 \quad 13,3$

23

$15,3 \quad 103$

68,7

10- Meu professor escuta como eu gostaria de fazer as coisas

RD

D

N/C N/D

C

RC

(f) $\quad(\%)$

(f)

$(\%)$

(f)

(\%)

(f)

$(\%)$

$(f)$

(\%)

12

8

3

$2 \quad 42$

28

30

20

63

42

11- Meu professor lida muito bem com as emoções das pessoas

\begin{tabular}{cccccccccc}
\multicolumn{2}{l}{ RD } & \multicolumn{2}{c}{ D } & \multicolumn{2}{c}{ N/C N/D } & \multicolumn{2}{c}{ C } & \multicolumn{2}{c}{ RC } \\
$(f)$ & $(\%)$ & $(f)$ & $(\%)$ & $(f)$ & $(\%)$ & $(f)$ & $(\%)$ & $(f)$ & $(\%)$ \\
11 & 7,3 & 5 & 3,3 & 32 & 33,9 & 20 & 13,3 & 82 & 54,7
\end{tabular}

12- Eu sinto que meu professor se preocupa comigo como pessoa

RD

D

N/C N/D

C

RC

$(f)$

$(\%)$

$(f)$

$(\%)$

$(f)$

$(\%)$

$(f)$

$(\%)$

$(f)$

(\%)

9

$6 \quad 6$

$4 \quad 35$

23,3

22

$14,7 \quad 84$

56

13- Eu não me sinto bem com a maneira que meu professor esclarece minhas dúvidas

RD

D

N/C N/D

C

RC

$\begin{array}{cccccccccc}(f) & (\%) & (f) & (\%) & (f) & (\%) & (f) & (\%) & (f) & (\%) \\ 84 & 56 & 3 & 2 & 35 & 17,7 & 12 & 8 & 26 & 17,3\end{array}$

14- Meu professor tenta compreender como eu percebo as coisas, antes de sugerir uma nova maneira de fazê-la
RD
D
N/C N/D
C
RC
$(f)$
$(\%)$
$(f)$
$(\%)$
(f)
(\%)
(f)
(\%)
(f)
(\%)
12
8
6
4
$36 \quad 23,9$
23
15,3
73
48,7

15- Me sinto capaz de compartilhar/dividir meus sentimentos com meu professor

RD

D

N/C N/D

C

RC

\begin{tabular}{llllllllll}
$(f)$ & $(\%)$ & $(f)$ & $(\%)$ & $(f)$ & $(\%)$ & $(f)$ & $(\%)$ & $(f)$ & $(\%)$ \\
31 & 20,7 & 8 & 5,3 & 45 & 30 & 14 & 9,3 & 52 & 34,7 \\
\hline
\end{tabular}

Fonte: os autores

Para colaborar com as compreensões da percepção alunos da EJA acerca da autonomia, o questionário utilizado apresenta questões destinadas a ações/sentimentos internos dos alunos (questões $1 ; 2 ; 3 ; 5 ; 8 ; 12 ; 13 ; 15$ ) e as ações interventivas dos professores para com os alunos (questões $4 ; 6 ; 7 ; 9 ; 10 ; 11$ e 14). Os dados indicaram que tanto nas questões referentes aos alunos, como nas referentes ao professor, foram encontrados maiores índices nas indicações de incentivo a autonomia, já que grande parte dos alunos realmente 


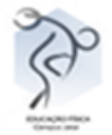

concorda que o professor oferece escolhas e opções para a realização das tarefas e ações desenvolvidas durante a aula $(f 82 ; 54,7 \%)$, apontam que são compreendidos pelo seu professor $(f 75 ; 50 \%)$, que conseguem se expressar com seus professores durante as aulas $(f$ $88 ; 58,7 \%)$, que se sentem aceitos pelos professores $(f 113 ; 75,3 \%)$ e sentem muita confiança no mesmo ( $f 94 ; 62,7 \%)$, reconhecendo que o professor se preocupa com ele enquanto pessoa e não apenas como aluno $(f 84 ; 56,0 \%)$, o que os fazem se sentir bem com a maneira que meu professor esclarece suas dúvidas ( $f 84 ; 56,0 \%)$, estimulando-os a compartilhar/dividir sentimentos com o professor $(f 52 ; 34,7 \%)$.

Em relação às ações interventivas dos professores para com os alunos, foi observado que a maioria dos alunos concorda que os professores confiam na capacidade dos alunos apresentarem bom desempenho ( $f 82 ; 54,7 \%$ ), se certificam se os alunos entenderam os objetivos da aula e o que deve ser feito $(f 98 ; 65,3 \%)$, assim como incentivam os alunos a fazerem perguntas $(f 74 ; 49,3 \%)$, respondendo-as de forma completa e cuidadosa ( $f 103$; $68,7 \%$ ). Além disso, os alunos atestam que o professor permite sua opinião e contribuições para a realização das tarefas $(f 63 ; 42 \%)$, buscando compreender como eles percebem as ações propostas, antes de sugerir uma nova maneira de fazê-la $(f 73,48,7 \%)$, destacou-se ainda o fato dos alunos indicarem que o professor "sabe lidar bem com a emoção das pessoas", ou seja, considera as emoções e sentimentos dos alunos durante a realização das tarefas apresentadas $(f 82 ; 54,7 \%)$.

Entretanto, mesmo com os valores positivos encontrados nos itens analisados, nota-se que em todas as questões apresentadas há um grande percentual de alunos que se posicionaram (não concordam nem discordam), o que demonstra que ainda há uma dificuldade ou desinteresse por parte dos alunos da EJA em avaliar a postura pedagógica dos professores em relação ao incentivo a autonomia, afinal segundo Veiga (2000) a autonomia no contexto educacional se relaciona as regras e orientações criadas pelos sujeitos, sem imposições externas, durante as situações de aprendizagem.

Moura (2016) destaca que as estratégias didático-pedagógicas adotadas pelo professor têm forte influência no envolvimento do aluno com as ações propostas, este clima de aprendizagem pode ou não favorecer as interações, as manifestações de opiniões e o bom relacionamento necessário para o bom andamento das aulas. 
Uma participação mais discreta por parte dos alunos do EJA também pode se dar pelo fato de que às vezes os mesmos percebem o professor "como alguém superior", respaldados por uma imagem constituída, numa educação nos moldes tradicionais, pautada no autoritarismo, na qual o professor é o detentor do conhecimento, sendo a participação dos alunos limitadas. Sobre essa forma de ensino, Freire (1997) coloca que quando o professor em sua forma de ensinar se pauta em uma postura autoritária, acaba por limitar a movimentação física e a fala do aluno, já que a disciplina é um pré-requisito para o ensino e isso restringe a caminhada conjunta e a troca de experiências e valores. Afinal, o retorno ao ensino, para os alunos da EJA, em geral já apresenta em si considerações marcadas pela historicidade social e econômica do sujeito que acaba por influenciar sobremaneira a forma que o mesmo tem em relação a espaço educativo.

Reeve e Jang (2006) avaliaram os comportamentos instrucionais de apoio à autonomia e controle dos professores. Para os autores, ao promover a autonomia, o professor aprende a ouvir os estudantes, favorece sua escolha permitindo que realizem as tarefas em seus próprios caminhos e, além disso, elogia os alunos, fornecendo informações adequadas durante as aulas; ações necessárias como evidenciadas nos resultados apresentados no estudo por meio dos dados dos alunos, especialmente na situação do ensino da EJA.

Outro entrave na posição crítica dos alunos ao responderem o questionário pode ser o fato de, ao estar longe do contexto escolar por variadas razões, o aluno retorna ao sistema de ensino com sua autoimagem fragilizada o que resulta em sentimento de insegurança, devido às várias derrotas enfrentadas em um processo escolar anterior (BRASIL, 2006; SANTOS, 2014), o que leva a abstenção frente a problemas e situações cotidianas, conforme indicado nos estudos realizados por Gomes e Carnielli (2003).

Deste modo, o professor precisa permitir que o processo de ensino e aprendizagem estabeleça o diálogo com os alunos, possibilitando a construção de novos conhecimentos. Afinal, como nos alerta Stevenson (2018), a educação deve ser uma ação de construção participativa do sujeito na sociedade e, portanto, a escola é o espaço indicado para essa ação ser evidenciada. Freire (1993) e Nascimento e Hetkowsi (2007) apontam que respeitar as experiências, motivações, sonhos, frustrações, dúvidas e desejos dos sujeitos deste 


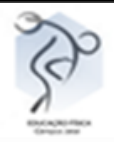

nível de ensino é de suma importância para o processo, uma vez que esses se colocam como ponto de partida para a ação pedagógica.

Outro aspecto importante destacado pelo estudo, foi em relação a forma como o conteúdo vem sendo trabalhado na EJA, considerada satisfatória aos seus alunos, acenando apenas para o fato de que ainda se faz necessária atenção às questões pedagógicas, em especial no que diz respeito à compreensão, participação nas aulas, construção dos conteúdos a partir de seus interesses e conhecimentos prévios e da abertura ao compartilhamento de sentimentos, para além dos conteúdos.

Esse entendimento se dá pela compreensão de que as aulas da EJA devem sustentar-se na premissa de uma elaboração participativa dos saberes, conhecimentos e conteúdos tratados, que considerem as necessidades e a realidade dos envolvidos, para que possam assim ter significado e valoração para os mesmos. Isso poderá garantir ao aluno uma visão do todo, viabilizando a diferenciação e reconciliação de significados, critérios, propriedades e categorias, que leve o aluno a uma aprendizagem significativa.

Há que se entender que o processo de ensino e aprendizagem na EJA se dá pela interação entre professores e alunos, uma vez que aprendizagem significativa se manifesta por meio da linguagem que viabiliza o compartilhar significados, gerando interações perturbadoras, que resultam em mudanças estruturais, sem perder a organização e identidade do processo (Nogueira; Leal, 2015).

Na EJA o professor deve trazer ao contexto de sala de aula um ambiente ativo e dinâmico, que favoreça o convívio da turma, para se construir situações de aprendizagem por meio de uma ação coletiva, superando as dificuldades dos alunos. Ao se utilizar e considerar a afetividade dentre as estratégias pedagógicas, nota-se que os alunos se sentem aceitos e reconhecidos como cidadão, em seus direitos e deveres, posicionando-se de modo aberto às trocas propostas (SILVA; SILVA, 2016), afinal como já afirmava Freire (1997) a formação e atuação docente não podem ficar distantes de práticas relacionadas às emoções, sensibilidades e afetividade, uma vez que é por meio destes sentimentos que se identificam lacunas que podem nortear as estratégias a serem adotadas.

Rodrigues e Moura (2016) apontam que para que o aluno aprenda é preciso que esse se perceba como agente ativo do processo de ensino e de aprendizagem assim, o 


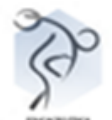

professor precisa atuar como facilitador da aprendizagem, colaborando para o desenvolvimento da consciência e para a compreensão dos conteúdos e sua aplicabilidade na resolução de problemas, passando o aluno da posição periférica para a central da ação, influenciando na sua percepção de autonomia.

E, em especifico sobre a autonomia pode-se observar que este estudo demostrou que os alunos apresentam alto índice de autonomia, resultado diferente do encontrado por Freith e Alencar (2006), que ao estudar percepção de alunos do ensino fundamental quanto ao clima de sala de aula para a criatividade constatou que o fator relativo à autonomia é baixo, denotando como algo pouco explorado neste nível de ensino. Esse fato leva a crer que há indicativos de mudanças de concepção sobre o aluno da EJA vendo-o como um ser adulto, independente e com biografia a ser aproveitada ao longo das aulas, mesmo que essa concepção ainda esteja sendo pouco explorada.

\section{CONSIDERAÇÕES FINAIS}

Diante dos resultados apresentados constata-se que, apesar dos alunos perceberem alto índice de autonomia nas situações de aprendizagem ao longo das aulas de Educação Física, ainda se fazem necessárias ações que aproximem os professores dos alunos de modo a reconhecer as expectativas e experiências prévias dos mesmos em relação aos conteúdos e ações, deixando-os mais confortáveis e motivados a participar das aulas e conteúdos propostos.

Ao se apoiar nesses elementos os professores podem trazer os alunos para perto de si, tornando o processo de ensino e de aprendizagem mais prazeroso, diminuindo a barreira que separa professor aluno e a participação nas aulas, favorecendo a autonomia ao longo do processo.

Assim, faz-se necessário que o professor em sua forma de ensinar busque compreender os diferentes aspectos psicológicos inerentes ao contexto educacional, pois este representa o primeiro momento de socialização dos alunos, exercendo grande impacto na vida destes sujeitos, no seu comportamento e nas situações de aprendizagem. 


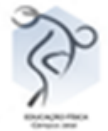

\section{REFERÊNCIAS}

AMES, Carole. Classrooms: goals, structures, and student motivation. Journal of Educational Psychology, Washington, v. 84, n. 3, p. 261-271, 1992.

ASSOR, Avi. et al. Directly controlling teacher behaviors as predictors of poor motivation and engagement in girls and boys: the role of anger and anxiety. Learning and Instruction, Holanda, v. 15, p. 397-413, 2005.

BRASIL, Lei de Diretrizes e Bases da Educação Nacional. 9394/1996, de 20 de dezembro de 1996. Estabelece as diretrizes e bases da educação nacional. Diário Oficial [da] República Federativa do Brasil, Brasília, DF, v. 20, 23 de dezembro de 1996.

BRASIL. Diretrizes Curriculares da Educação de Jovens e Adultos. Curitiba, 2006.

BRASIL. Ministério da Educação. Parecer CNE/CEB $n^{\circ} 11$, de 10 mai. 2000. Estabelece as Diretrizes Curriculares Nacionais para a Educação de Jovens e Adultos, 2000.

BRASIL. Secretaria de Educação Fundamental. Parâmetros curriculares nacionais: pluralidade cultural, orientação sexual. Brasília, DF: MEC/SEF, 1997.

BRASIL. Conselho Nacional de Educação. Resolução CNE/CEB nº1 de 2000. Dispõe sobre as Diretrizes Curriculares Nacionais para a Educação de Jovens e Adultos. Brasília, DF: CNE, 2000.

CASTRO, Amélia Domingues de; CARVAlHO, Anna Maria Pessoa de; PÉREZ, Daniel Gil. Ensinar a ensinar: didática para a escola fundamental e média. São Paulo: Copyright de Pioneiras, 2001.

CASTORIADIS, Cornelius. A instituição imaginária da sociedade (título original: L'Institution imaginaire de la Societé, Paris, Éditions du Seuil, 1975); tradução de Guy Reynaud, Rio de Janeiro: Paz e Terra, 1991.

COX, Anne E. et al. Change in physical education motivation and physical activity behavior during middle school. Journal of adolescent health, San Francisco, v. 43, n. 5, p. 506-513, 2008.

DA COSTA, Luciane Cristina Arantes et al. Validação do Learning Climate Questionnaire (LCQ): um questionário para avaliação do clima de aprendizagem. Revista de Educação Física/Journal Of Physical Education, Rio de Janeiro, v. 85, n. 2, p, 102- 108, 2016. 


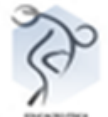

DECI, Edward L.; RYAN, Richard M. The "what" and "why" of goal pursuits: Human needs and the self-determination of behavior. Psychological Inquiry, cidade?, v. 11, p. 227-268, 2000 .

FREIRE, Paulo. A educação na cidade: projeto pedagógico, 1991.

FREIRE, Paulo. Pedagogia da indignação: cartas pedagógicas e outros escritos. São Paulo: UNESP, 1993.

FREIRE, Paulo. Pedagogia da autonomia: saberes necessários à prática educativa. São Paulo: Paz e Terra, 1997.

FREITH, Dense de Souza; ALENCAR, Eunice Maria L. Soriano de. Percepção de alunos do ensino fundamental quanto ao clima de sala de aula para criatividade. Psicologia em Estudo, Maringá, v. 11, n. 3, p. 513-521, 2006.

GADOTTI, Moacir. Ação pedagógica e prática social transformadora. Educação e Sociedade, Campinas, v. 1, n. 4, p. 5-14, 1979.

GADOTTI, Moacir. Uma só escola para todos: caminhos da autonomia escolar. Produção de terceiros sobre Paulo Freire; Série Livros, Petrópolis: Vozes, 1990.

GADOTTI, Moacir. Escola cidadã: uma aula sobre a autonomia da escola. São Paulo: Cortez, 1992.

GERHARDT, Tatiana Engel; SILVEIRA,Denise Tolfo. Métodos de pesquisa. Porto Alegre: Editora da UFRGS, 2009.

GOLDSCHMIDT FILHO, Francisco; DA CRUZ, Lucas Lopez; BOSSLE, Fabiano. Educação Física na EJA: desafios e possibilidades. Kinesis, Santa Maria, v. 34, n. 2, p. 117- 131, 2016.

GOMES, Candido Alberto; CARNIELLI, Beatrice Laura. Expansão do ensino médio: temores sobre a Educação de Jovens e Adultos. Cadernos de Pesquisa, n. 119, p. 47-69, julho/ 2003.

GREGORY, Gayle H. Creating a climate for learnig. In. Gregory, G. H.; Chapman, C. Differentiated Instructional Strategies in Practice: Training, Implementation, and Supervision. 2 ed. Thousand Oaks, CA: Corwin Press; 2008.

GÜNTHER, Maria Cecília Camargo. O direito à educação física na educação de jovens e adultos. Revista Brasileira de Ciências do Esporte, Brasília, DF, v. 36, p. S400-S412, 2016.

LEMOS, Carlos Augusto Fogliarini. Qualidade de vida na carreira profissional de professores de educação física do magistério público estadual/RS. $115 \mathrm{f}$. Dissertação (Mestrado em Educação Física) - Centro de Desportos, Universidade Federal de Santa 


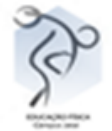

Catarina, Florianópolis,2007.Disponível em: <http://tede.ufsc.br/teses/PGEF0152.pdf>. Acesso em: out. 2017.

LOPES, Edjonas Silvana; SILVANA, Francimária Sousa Santos; DAMASCENO, Eronilda Gomes. Campanhas de Educação de Jovens e Adultos-EJA: Aspectos Históricos e Avanços. Revista de Psicologia, Fortaleza, v. 10, n. 32, p. 147-163, 2016.

MAYAN, Maria J. A introduction qualitative methods: a training module for student sandprofessionals. Edmonton, Universidade of Aberta, 2001.

MELLO, Guiomar Namo de. Magistério de $\mathbf{1}^{\mathbf{0}}$ grau: da competência técnica ao compromisso político. 10. Ed. São Paulo: Cortez, 1993.

MESQUITA, Isabel et al. Representations of the students and their teacher about the educational value of Sport Education Model within an athletic unit/Representacao dos alunos e professora acerca do valor educativo do Modelo de Educacao Desportiva numa unidade didatica de atletismo. Motricidade, Portugal, v. 12, n. 1, p. 26-43, 2016.

MOREIRA, Marcos Antônio. Aprendizagem significativa: a teoria e textos complementares. São Paulo: Editora Livraria da Física, 2011.

MOREIRA, Wagner Wey et al. Corporeidade: uma base epistemológica para a ação da Educação Física. Motrivivência, Florianópolis, v. 29, n. 50, p. 202-212, 2017.

MORIN, Edgar. Os sete saberes necessários à educação do futuro. São Paulo: Cortez, Brasília: Unesco, 2001.

MOURA, Anaisa Alves de et al. Fatores condicionantes da aprendizagem de adultos: estudo realizado na escola de ensino fundamental Antenor Naspolini. Dissertação de Mestrado apresentada a Universidade Lusófona de Humanidades e Tecnologias, 2016.

NASCIMENTO, Antônio Dias; HETKOWSKI, Tânia Maria. Memória e formação de professores. 2007.

NOGUEIRA, Makeliny Gomes; LEAL, Daniela. Teorias da aprendizagem: um encontro entre os pensamentos filosóficos, pedagógicos e psicológicos. 2ed. Curitiba: Editora Intersaberes, 2015.

PIERRO, Maria Clara di; JOIA, Orlando; RIBEIRO, Vera Masagão. Visões da educação de jovens e adultos no Brasil. Cadernos Cedes, Campinas, v. 21, n. 55, p. 58-77, 2001.

PROJETO POLÍTICO PEDAGÓGICO (PPP). Centro Estadual de Educação Básica para Jovens e Adultos. Maringá, 2016. 


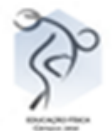

REEVE, Johnmarshall; JANG, Hyungshim. What teachers say and do to support students' autonomy during a learning activity. Journal of educational psychology, Washington, v. 98, n. 1, p. 209, 2006.

RODRIGUES, Francisco das Chagas Alves; MOURA, Maria da Glória Carvalho. Aprendizagem no contexto da modalidade Educação de Jovens e Adultos (EJA): uma reflexão à luz da Andragogia. PerCursos, Florianópolis, v. 17, n. 34, p. 112-133, 2016.

SANTOS, Fábio Mauricio. Afetividade na Prática Docente como Forma de Combater a Evasão Escolar: Experiência com Alunos do Instituto Luciano Barreto Júnior. Caderno Intersaberes, cidade?, v..3, n.4, p.117 - 127, 2014.

SILVA, Silvia Leticia Losada; SILVA, Tatiana Luna Gomes. A afetividade como ferramenta pedagógica no processo de ensino-aprendizagem de jovens e adultos. E-Mosaicos, Rio de Janeiro, v. 5, n. 10, p. 67-80, 2016.

SOUZA, Maria Antônia de. Educação de jovens e adultos. Curitiba: Editora Intersaberes, 2012.

STEVERSON, Nick. A educação de a alteridade da democracia. Caderno de Pesquisa, v.48, n.167, p.150-171, jan/mar, 2018.

THOMAS, J.R.; NELSON, J.K. Métodos de pesquisa em atividade física. 3.ed. Porto Alegre: Artmed, 2002.

VALLE, Luciana de Luca Dalla. Metodologia da Alfabetização. Curitiba: Editora Intersaberes, 2013.

VEIGA, Ilma Passos Alencastro. Projeto Político-Pedagógico da escola: uma construção possível. 10ed. Campinas, SP: Papirus , 2000.

VIEGAS, Ana Cristina Coutinho; MORAES, Maria Cecília Sousa de. Um convite ao retorno: relevâncias no histórico da EJA no Brasil. Revista Ibero-Americana de Estudos em Educação, Araraquara, v. 12, n. 1, p. 456-478, 2017. 